\title{
Asilos en dictaduras: \\ chilenos en la embajada argentina
}

\author{
Soledad Lastra, ${ }^{*}$ Carla Peñaloza Palma**
}

Perfiles Latinoamericanos, $24(48)$

2016 | pp. 83-109

DOI: $10.18504 / \mathrm{pl} 2448-004-2016$

\begin{abstract}
Resumen
En la historiografía de los exilios políticos masivos del Cono Sur, los asilos diplomáticos constituyen un área de vacancia. Este artículo recorre las experiencias de chilenos y chilenas asilados en la embajada argentina en Santiago de Chile a partir del golpe militar del 11 de septiembre de 1973 y hasta 1974. Se explora cómo se realizaron los ingresos a la embajada argentina, las relaciones de los diplomáticos con los asilados y con el contexto general, las rutinas y aspectos cotidianos de la vida en la embajada y la salida hacia Argentina una vez obtenidos los salvoconductos. Se presta especial atención a los modos en que las dinámicas políticas de Chile y Argentina atravesaron a estas experiencias. El artículo se posiciona en el nudo álgido de dos historias nacionales y de la experiencia del asilo diplomático en sus múltiples matices y complejidades.
\end{abstract}

\begin{abstract}
In the historiography of the massive political exiles in the Southern Cone, the field of diplomatic asylum offers an area of vacancy. This article review the experience of Chileans that received asylum in the Argentinean embassy in Santiago de Chile from the military coup d'état in September 111973 until 1974. The article explore the way people have got in to the embassy, the relationships between diplomatic personal and the asylees and the everyday life and the finally travel to Argentina. This work pays special attention to the way political dynamics in Chile and Argentina experienced this process. The article addressed an algid point of two national histories and analyses the political asylum experience in its multiple facets and complexities.
\end{abstract}

Palabras claves: asilo diplomático, exilios, represión, experiencias, Embajada de Argentina, Chile. Keywords: Diplomatic asylum, exiles, repression, experiences, Embassy of Argentina, Chile.

* Doctora en Historia, Universidad Nacional de La Plata (Argentina). Instituto de Altos Estudios Sociales, Universidad Nacional de San Martín; CONICET.

** Doctora en Historia, Universidad de Barcelona (España). Departamento de Ciencias Históricas, Facultad de Filosofía y Humanidades, Universidad de Chile. 


\section{Introducción}

l golpe de Estado del 11 de septiembre de 1973 impactó de manera profunda sobre el pueblo chileno, con alcances represivos que no pudieron ser anticipados. Además de las persecuciones, detenciones y muertes, el régimen autoritario dispuso de otras herramientas para marginar y silenciar a distintos sectores sociales y políticos del país. Una de esas herramientas fue la expulsión del territorio nacional de miles de chilenos y de extranjeros residentes en Chile, especialmente de aquellos que habían llegado durante la presidencia de Salvador Allende, huyendo de las dictaduras del resto del continente, pero también de quienes habían llegado a Chile en los años de la Unidad Popular para ver y vivir en primera persona aquel experimento político social considerado como ejemplar para los que quisieron implicarse directamente en este proceso histórico.

El exilio político formó parte de un complejo entramado represivo que contó con pilares legales desplegados por la dictadura militar chilena. El 6 de noviembre de 1973, la expulsión de nacionales y extranjeros fue formalizada a través del Decreto-Ley número 81 (06/11/1973), que otorgó al Estado la facultad de expulsar del país a quienes cometieran delitos y dispuso que las personas que desearan regresar al territorio nacional podrían hacerlo solo con previa autorización del Ministerio del Interior. Este decreto, junto a otros importantes instrumentos jurídicos ${ }^{1}$ desplegados en los años siguientes, evidencian que el gobierno de facto se adjudicó a través de una regulación arbitraria, la facultad de decidir quién podría vivir o no en el país y, aún más, de marcar la suerte de distintas personas a partir de la catalogación como "subversivos" o potenciales "amenazas" para el orden social chileno.

Aunque no existen cifras precisas, se estima que más de cuatrocientas mil personas $^{2}$ vivieron su exilio como consecuencia del accionar represivo militar.

1 Además del Decreto-Ley número 81, se sancionó el Decreto-Ley 604 (10/08/1974) que prohibía el ingreso al territorio nacional de las personas consideradas "peligrosas" por el régimen; el decreto supremo 504 del Ministerio de Justicia (04/1975) que permitió que las personas condenadas por tribunales militares conmutasen su pena por el "extrańamiento" sin poder regresar aunque se hubiese cumplido el tiempo de condena afuera del país. Junto a ello, el 11 de marzo de 1981 entró en vigencia la Constitución nacional de 1980, en cuyo artículo 24 afirmaba el poder del presidente para expulsar del territorio o prohibir el ingreso de todas aquellas personas consideradas activistas y difusoras de doctrinas contrarias a los intereses del Estado.

2 Según la Liga Chilena de Derechos del Hombre fueron cuatrocientos mil los chilenos y chilenas que debieron abandonar el país por razones políticas, cifra que duplica a las entregadas por otros organismos. De acuerdo a los datos manejados en 1990 por la Oficina Nacional de Retorno, el Servicio Universita- 
En general, hay acuerdos entre los especialistas del tema en considerar al exilio chileno como un proceso iniciado de forma abrupta y masiva el mismo día en que se produjo el golpe de Estado (Ońate, Wright, Espinoza, Soto \& Galleguillos, 2006; Del Pozo, 2006; Norambuena, 2000; Sznajder \& Roniger, 2013). Sin embargo, esta oleada emigratoria tuvo sus gradaciones y mantuvo flujos de ingresos y egresos del país a lo largo de todo el periodo autoritario. ${ }^{3}$

$\mathrm{Al}$ igual que otros exilios del Cono Sur, el chileno es un objeto poliédrico y móvil (Jensen, 2011), formado por múltiples experiencias, complejas y heterogéneas, que tuvo distintas formas y diversos tiempos de salida y destinos. ${ }^{4}$ Los caminos para salir al exilio fueron variados, determinados por las circunstancias y las posibilidades de cada persona, pero fue muy importante el apoyo que las organizaciones de derechos humanos y los distintos Estados otorgaron a los perseguidos políticos en Chile. Debido al cierre de las fronteras y a la persecución, detención y fusilamiento de ciudadanos chilenos y extranjeros, el Alto Comisionado de las Naciones Unidas para los Refugiados (ACNUR), así como otras organizaciones no gubernamentales y actores de las Iglesias católica y protestante, ${ }^{5}$ fueron fundamentales para proteger a los perseguidos políticos y orientar sus salidas del país. Uno de esos caminos fue el del asilo diplomático, es decir, buscar refugio en una embajada o consulado. Las legaciones diplomáticas se sumaron al esfuerzo de protección humanitaria. Hacia julio de 1974, la Comisión Interamericana de Derechos Humanos (CIDH) de la Organización de Estados Americanos (OEA) estimaba que el gobierno habría permitido la salida del país de 4948 extranjeros y de 2945 chilenos asilados en distintas embajadas en Santiago ${ }^{6}$ (CIDH, 1974). Así, el exilio —en sus múltiples rostros, tiempos,

rio Mundial y Comité Intergubernamental para las Migraciones, los exiliados políticos representaban alrededor de doscientas mil personas dispersas entre los cinco continentes. Esta cifra del exilio político es cercana a la de la Vicaría de la Solidaridad, que registra unas doscientas sesenta mil personas que fueron obligadas a vivir fuera del país por razones políticas (Rebolledo: 2006). Sin embargo, a partir de las propias fuentes de la Vicaría, Carmen Norambuena (2000) calcula que habrían salido del país cuatrocientas ocho mil personas.

3 Por ejemplo, hubo una gran emigración con las protestas sociales de 1983 y 1986, mientras en paralelo comenzaban a efectuarse los retornos de aquellas personas que estaban siendo autorizadas por el Ministerio del Interior para regresar al país, sobre todo desde 1982 cuando estos permisos se expidieron con mayor frecuencia (Sznajder \& Roniger, 2013: pp. 361-362).

4 De acuerdo con Carmen Norambuena (2000), los principales destinos de los exiliados chilenos fueron: Argentina (50.78\%), Estados Unidos (7.87\%), Venezuela (6.18\%), Canadá (3.85\%), Francia (3.68\%), Italia (2.38\%), Suecia (2.38\%) y Australia (2.21\%).

5 Muchos de estos organismos estuvieron vinculados al Comité Nacional de Ayuda a los Refugiados (CONAR), que fue creado con el Decreto 1308 del 3 de octubre de 1973, como parte del acuerdo entre el ACNUR y el gobierno de Chile para ayudar a los extranjeros a viajar hacia otros países.

6 De acuerdo con un informe del ACNur (2000), las embajadas más concurridas fueron las de Argentina, Francia, Italia, México, los Países Bajos, Panamá, Suecia y Venezuela. 
destinos y formas - fue uno de los efectos que atravesó en su masividad y en su generalidad a la sociedad chilena.

El asilo diplomático se consolidó durante el siglo xx como una herramienta latinoamericana de protección a perseguidos políticos. Como explica Silvia Dutrénit Bielous (1999), si bien como institución el asilo ha sido debatido y consensuado por distintos países latinoamericanos, ${ }^{7}$ lo cierto es que a partir de las experiencias represivas que atravesaron al Cono Sur quedó claro que esta herramienta contaba con importantes lagunas normativas y de regulación para aplicar ese derecho. En este sentido, las distintas experiencias del asilo diplomático dependieron, en parte, de las condiciones específicas de cada momento histórico y de la particularidad de la legación a cargo, especialmente en relación a tres aspectos: las valoraciones de los diplomáticos a cargo de brindar el asilo, las estrategias estatales de los gobiernos involucrados y las características de los perseguidos políticos (Dutrénit, 1999: p. 111), por nombrar las más importantes.

En la presente investigación abordaremos una experiencia de exilio que, hasta la fecha, ha sido poco estudiada: los asilados en la Embajada de Argentina en Santiago de Chile. ${ }^{8}$ Para ello tomaremos un espacio temporal que va del golpe de Estado hasta finales de 1974, momento en que hubo una serie de hechos, disposiciones y decisiones tomadas por las legaciones diplomáticas latinoamericanas y europeas que significaron el declive de los pedidos de asilo. ${ }^{9}$ En esa coyuntura, las experiencias del asilo en la embajada estuvieron marcadas por las condiciones políticas y sociales del golpe militar en Chile y también por el álgido momento político que se vivía en Argentina: con una fuerte radicalización política de las organizaciones de izquierda en el marco del traspaso presidencial

7 Recordemos que la figura del asilo ha transitado por diversas convenciones: la de La Habana en 1929, la de Montevideo en 1933 y luego en 1939 y, finalmente, la de Caracas en 1954. El asilo diplomático lo ofrece un Estado en territorio extranjero amparado en la prerrogativa del principio de extraterritorialidad, mientras que el asilo territorial — del que no nos ocupamos aquí- es el que ofrece un Estado en su propio territorio a una persona que proviene de otro Estado (Dutrénit, 1999). En el caso del asilo diplomático es importante remarcar que la figura del asilo la otorga el Estado asilante (en este caso, Argentina), mientras que el salvoconducto — la herramienta jurídica que permite la salida del país— la otorga el Estado territorial (en este caso, Chile).

8 Agradecemos la lectura y comentarios de las doctoras Silvina Jensen y Silvia Dutrénit Bielous a versiones preliminares de este texto. Las consideraciones aquí volcadas son de nuestra exclusiva responsabilidad.

9 Entre otros aspectos, esto se debió al aviso dado el 11 de diciembre de 1973 por el régimen militar en el que dispuso la no entrega de salvoconductos de cortesía para las personas que solicitaran asilo en adelante. Junto a ello, fueron distintos los gobiernos que rompieron relaciones con Chile y que retiraron su personal diplomático del país (Suecia, Cuba, Bégica, Italia, México, Colombia, entre otros). Además, debemos tener en cuenta que, en octubre de 1974, quedaban solo nueve chilenos asilados en la embajada de Italia (CIDH, 1974). 
de Raúl Lastiri a Juan Domingo Perón en octubre de $1973 ;{ }^{10}$ y posteriormente por la muerte de Perón en julio de 1974 que fue reemplazado por su viuda, Isabel Martínez de Perón, abonando al proceso de recrudecimiento del aparato represivo estatal y paraestatal (Franco, 2012). En ese marco, gran parte de la emigración política chilena -más del $50 \%$ de acuerdo con Norambuena (2000) - cruzó las fronteras hacia Argentina, de forma individual o con su grupo familiar. ${ }^{11}$ De esta manera, entendemos que las experiencias del asilo en la embajada no se limitan al tiempo de permanencia en la legación diplomática sino que también incluye la vivencia del arribo hacia Argentina, dado que este país sufría por entonces de una fuerte ebullición política y social que afectaba también a algunas dinámicas de la embajada y del asilo.

Esta investigación se nutre de distintos trabajos empíricos elaborados sobre otras experiencias de asilo en el Cono Sur (Dutrénit \& Rodríguez, 1999; Dutrénit, 2011; Camacho, 2006; Yankelevich, 2009, entre otros) con el propósito de preguntarse por la especificidad de la embajada argentina en Santiago de Chile. Para ello se consultaron entrevistas realizadas a chilenos y chilenas que recibieron asilo en la embajada entre 1973 y 1974, así como notas de prensa de ambos países e informes de los servicios de inteligencia de la Policía de la Provincia de Buenos Aires durante ese breve periodo. ${ }^{12}$ Estos informes nos permitirán pensar cómo las experiencias de los asilados estuvieron atravesadas tanto por las tensiones políticas propias del golpe en Chile como por los conflictos políticos internos que vivía Argentina en ese momento, en especial en relación a la gradual construcción de la figura del "otro" como un enemigo del orden nacional. ${ }^{13}$

10 Recordemos que Lastiri asumió como presidente interino en julio de 1973 debido a la renuncia al poder del entonces presidente Héctor Cámpora, de cara a la celebración de nuevas elecciones presidenciales en las que Juan Domingo Perón podría participar sin condicionamientos. Perón ganó las elecciones con el $62 \%$ de los votos y asumió en octubre de ese ańo.

11 Para el caso argentino, en particular de los exiliados chilenos que arribaron a Mendoza y Chubut, Paredes (2007) y Gatica (2010) coinciden en subrayar el perfil obrero y de clase trabajadora de estos emigrados.

12 Este estudio se apoya especialmente en las entrevistas realizadas y resguardadas en Memoria Abierta, institución que nuclea y difunde la información documental de distintas organizaciones sociales y de derechos humanos en Argentina. Además de su archivo oral, Memoria Abierta ofrece a los investigadores y al público en general un portal de acceso a otros archivos de derechos humanos de Argentina, así como una serie de herramientas pedagógicas y de difusión sobre temas de memoria e historia reciente. Véase www.memoriaabierta.org.ar

13 Cabe aclarar que esta investigación adolece de una fuente oficial importante como es el fondo documental de la embajada argentina en Santiago entre los ańos 1973-1976, material que no ha sido desclasificado aún por el Ministerio de Relaciones Exteriores de Argentina. Estimamos que con su apertura se podrá avanzar en el conocimiento de estas experiencias y en la construcción de una historia política del asilo en la región. 
Sin ánimos de ofrecer una construcción acabada del asilo en esta embajada, nos proponemos presentar varios aspectos centrales de estas experiencias, inscritas en el nudo de dos historias nacionales álgidas y en tensión en esa coyuntura particular. En la primera parte, recorremos distintas modalidades de ingreso a la embajada argentina; en la segunda, profundizamos en las dinámicas cotidianas de la vida dentro de la legación; en la tercera, indagamos en el momento de la salida de la embajada y el arribo a la Argentina, señalando algunas tensiones en ese proceso y, por último, a modo de cierre, construimos diversas reflexiones.

\section{La embajada argentina como opción}

En el marco del golpe de Estado, buscar refugio en una legación diplomática no resultaba fácil, y se volvía más dificultoso según pasaban los días. Los militares chilenos rodearon las residencias y edificios del personal diplomático para evitar el ingreso de personas en busca de asilo. A pesar de la vigilancia, cientos de chilenos lograron entrar en algún tipo de recinto diplomático. Esto no habría sido posible sin la existencia de una red informal pero eficiente de organizaciones e individuos cuyo primer gesto de resistencia contra la dictadura fue la de ayudar a salir del país a los perseguidos. Además de saltar rejas, esconderse en automóviles, disfrazarse, y de utilizar otros recursos para despistar a los militares, ${ }^{14}$ fue importante la complicidad de los funcionarios diplomáticos. ${ }^{15}$

En términos generales las embajadas eran elegidas, sobre todo, por las facilidades de ingreso. Este fue el caso de la embajada argentina, ubicada en el centro de la ciudad. Los diplomáticos de esta embajada desde un primer momento comenzaron a recibir solicitudes de asilo de extranjeros, chilenos y también de muchos argentinos que deseaban regresar. La embajada no se encontraba preparada para ello, pues nadie lo estaba para recibir tal afluente de personas. $\mathrm{Al}$ momento del golpe de Estado, el embajador designado — Javier Teodoro Gallac - estaba ausente y en su lugar había quedado un grupo de diplomáticos que trabajó cotidianamente en el recibimiento y la asistencia a las personas que ingresaban. Uno de ellos era Albino Gómez, consejero de la embajada desde

14 Como explican Aguirre y Chamorro, la aventura de buscar asilo en las embajadas tuvo ribetes dramáticos, "la persecución, el instinto de sobrevivencia de los que intentaban salvar sus vidas y la gestión humanitaria de los funcionarios de las embajadas, se constituyeron en acciones de una misma escena, donde un acierto o un error marcaba la diferencia entre la vida y la muerte" (Aguirre \& Chamorro, 2008: p. 42). Las historias recabadas aquí, así como otras experiencias registradas en periódicos y fuentes gráficas de la época, abonan a esta mirada.

15 El caso del embajador mexicano Gonzalo Martínez Corbalá y del embajador sueco Haral Edelstam han sido los más recordados. 
agosto de 1972, que para el momento del golpe tenía pendiente su pase a la embajada argentina en Nicaragua. ${ }^{16}$

Para Gómez, el golpe militar irrumpió con una violencia inesperada y lo que siguió fue "la historia de recibir [gente], no hubo tiempo a pensar, ni meditar... empezar a recibir las consecuencias, recibir gente, asustada, con temor, no sabíamos cuán duro podría ser" (Memoria Abierta, Testimonio de Albino Gómez, Buenos Aires, 2013). De su relato se desprende que no hubo una fuerte organización para la recepción inmediata de los perseguidos, sino que se trataba sobre todo de "meter gente", tanta como fuera posible. Uno de los modos fue apoyando los simulacros que las mismas personas que llegaban al recinto realizaban frente a los carabineros y a los funcionarios del consulado, por ejemplo, fingiendo que se acercaban para hacer un trámite cuando, en realidad, estaban buscando algún tipo de protección diplomática. Así se cuenta:

Algunos iban a hacer trámites [al consulado] y tratábamos de hablar para ver si iban a hacer un trámite en serio o si estaban desesperados [...] Después empezó la cosa a ponerse fuerte que no podía entrar nadie, yo hablaba con [los carabineros], les ofrecía cigarrillos, les ofrecía soborno, había soborno a los milicos para que me dejaran pasar. Había días más flojos que no hacían tanta cuestión. O la gente ya venía instruida para preguntar por mí directamente o les decía que fueran directamente al consulado, preguntá al cónsul de parte mía. Al consulado dejaban pasar porque se hacían trámites, era más fácil entrar al consulado; la embajada ahí no eran oficinas, era residencia, bueno pero decíamos: vengan bien vestidos, vengan así, vengan asá, vengo a ver a fulano de tal (Memoria Abierta, Testimonio de Albino Gómez, Buenos Aires, 2013).

Como explica el exfuncionario, algunos ingresos a la embajada se realizaron por medio del consulado contando en algunos casos con la complicidad de los diplomáticos que aprendieron a "leer" las intenciones de las personas que se acercaban.

Otro modo de acceder a la embajada fue ingresando clandestinamente, saltando los muros del perímetro de la residencia o bien aprovechando los momentos de menor vigilancia de las puertas de entrada. Por ejemplo, Ana María Bussi sobrina de Salvador Allende y militante del Partido Socialista—, recuerda: "entramos por el hospital San Borja, vimos que había un estacionamiento y había

16 Junto a él se encontraban José Alberto del Carril —encargado de Negocios—, Héctor Carlos José Saiz Ballesteros — consejero de la Embajada y cónsul general—y Félix Alberto Córdova Moyano — secretario de la Embajada y cónsul de tercera-. Véase Decretos del Poder Ejecutivo Nacional núm. 877/73 (29 de agosto de 1973) y 1688/73 (3 de octubre de 1973). 
un muro... bueno, ¡era alto! Tampoco me puedo explicar cómo lo salté, yo en momentos normales no hubiera subido ni diez centímetros ese muro pero lo salté sin mayores dificultades" (Memoria Abierta, Testimonio de Ana María Bussi Vidal, Santiago, 2013). Otro de los asilados recuerda haber tomado la decisión de ingresar a la embajada luego de llevar adelante algunos estudios de la zona, evaluando los movimientos de las fuerzas policiales y la magnitud de los muros que habría que saltar: "alguien dijo que por el fondo, por el sitio Eriazo, se podía entrar... así que por allí entramos, éramos como seis creo [...] Primero privilegiamos a las mujeres, el muro era muy alto, es el mismo que está hoy día, pero el muro de ahí a un metro había un alambrado de púa" (Memoria Abierta, Testimonio de Mario Daniel Pérez Aguilar, Santiago, 2013). En ese escenario, los muros también fueron protagonistas de los ingresos de bebés y niños que eran lanzados por sus padres y familiares hacia los jardines de la residencia; estos hechos marcaron no solo a las personas que buscaban asilo sino a quienes los ayudaban y recibían (Memoria Abierta, Testimonios de Juan Tobar y Mario Daniel Pérez Aguilar, Santiago de Chile, 2013). Por ejemplo, Adriana Moreno cuenta cómo ayudó a mucha gente a entrar a la embajada argentina: "con las guaguas [bebés] en brazos andábamos ayudando a meter gente a las embajadas... yo no sé cómo no me tomaron detenida... había, en ese contexto, como un cierto resguardo de tu ser madre con guagua" (Entrevista a Adriana Moreno Fuenzalida, Santiago, 2013).

De acuerdo al testimonio de Albino Gómez, a los pocos días de producido el golpe militar se habría recibido un cable desde la Cancillería en el que se indicaba que la política debía ser de "puertas abiertas", disposición que se habría visto obstaculizada por la presencia de los carabineros que, en lugar de respetar esa decisión, las vigilaban y cerraban. ${ }^{17}$ En distintos casos se mencionan hechos de violencia en los ingresos a la embajada, por ejemplo, Francisco Martorell narraba en 2007: "hubo varios tiroteos de Carabineros contra la residencia, sé de alguien engañado por uno de ellos que simuló querer ayudarlo, y a quien fusilaron cuando subía la pared" (Clarín, 11/11/2007). Aunque en otros casos los perseguidos pudieron aprovechar cierta permisividad de los carabineros cuando dejaban la puerta sin vigilancia. ${ }^{18}$ Lo cierto es que, en esas múltiples experien-

17 Por ejemplo, Juan Tobar, empleado de la embajada argentina en esos años, menciona: "recuerdo que la orden del Ministerio allá era 'las puertas abiertas de la embajada', abiertos los portones y ellos los cerraban, los carabineros, y entonces ahí los diplomáticos peleando y me pedían ayuda los diplomáticos, abrir los portones, si era orden del Ministerio, las puertas abiertas para que se asile las personas y ellos las cerraban" (Memoria Abierta, Testimonio de Juan Tobar, Santiago de Chile, 2013).

18 Por ejemplo, otro asilado reconoce en su ingreso a la embajada cierta permisividad de los carabineros que "en algunas horas y de acuerdo a su propia percepción, se hacían los locos, y estaba abierta la puerta del estacionamiento y por ahí podíamos entrar... por ahí entramos" (Memoria Abierta, Testimonio de José Emilio Dollenz Briceño, Santiago de Chile, 2013). 
cias, la embajada argentina parece haber estado tan sitiada por las fuerzas de seguridad como el resto de las legaciones diplomáticas. ${ }^{19}$

En general, los relatos de algunos asilados indican que la embajada argentina fue una opción "a la mano" que dependía principalmente del fácil acceso que ofrecía ya sea saltando los muros o ingresando por otras vías. Sin dudas, la ubicación de la embajada, en pleno centro de la ciudad, facilitaba las cosas. Para Ana María Bussi la opción por Argentina no fue la primera en la lista, sino que formaba parte de los rumores que circulaban entre personas allegadas que veían en las embajadas un modo de salvar la vida: "la embajada de Japón tiene poca gente, yo pensaba ¿qué voy a hacer en Japón?, no, la embajada de Francia tiene menos guardia, [...] hasta que un día los militares llegaron al barrio y salimos nomás, y me dijeron 'no, vamos, súbete al auto y nos vamos a cualquier embajada, a la embajada que encontremos te vas" (Memoria Abierta, Testimonio de Ana María Bussi Vidal, Santiago de Chile, 2013). Para Adriana, en la elección de las embajadas el acceso era uno de los datos más importantes, así señala: "yo creo que todos los gobiernos abrieron sus puertas. Lo que pasa es que eran de más fácil acceso por los lugares donde estaban ubicados, las rejas que tenían" (Entrevista a Adriana Moreno Fuenzalida, Santiago, 2013).

Pero la ubicación urbana de la embajada no bastó para tomar la decisión de pedir asilo. Para otras personas esto también dependió de las directivas emitidas por sus partidos políticos y sus organizaciones ante el golpe militar. Aunque aún no contamos con investigaciones que analicen el lugar del exilio en las distintas estructuras políticas, podemos arriesgar que, en un primer momento, el Movimiento de Izquierda Revolucionaria (MIR) decidió no asilarse ni abandonar el país, ${ }^{20}$ mientras que el Partido Comunista y el Partido Socialista parecen no haber tenido una política clara al respecto.

Importantes investigaciones han señalado que una de las características más sobresalientes del exilio chileno fue su perfil político pues, a diferencia de otros exilios del Cono Sur, estuvo compuesto por importantes figuras del orden gubernamental depuesto y, a la vez, los exiliados lograron reconstituir a sus partidos

19 Como explica Camacho (2006: p. 23), "saltándose el derecho internacional, las fuerzas de seguridad chilenas se dedicaron a dificultar el papel humanitario de los distintos recintos diplomáticos. Para ello tomaron medidas de diverso tipo a veces dependiendo de la embajada que se tratara. Por lo general, se rodeaban los edificios diplomáticos de uniformados para evitar que nuevos asilados pudieran ingresar en ellos, pero en ocasiones se intimidó con detenciones del personal diplomático o dificultando el ingreso de víveres o medicinas".

20 Esto se habría modificado tras la dura represión sufrida en 1974, que significó la detención y desaparición de la mayoría de sus cuadros dirigentes y la muerte de su líder Miguel Enríquez, hasta que en 1978 el mir emprendió su política de "operación retorno". 
políticos ${ }^{21}$ en el extranjero, especialmente en Europa (Sznajder \& Roniger, 2013: pp. 284-285). De acuerdo con un funcionario de la embajada argentina, hacia finales de septiembre de 1973 no había entre los chilenos asilados ninguna figura política del gobierno de Allende (La Nación, 29/09/1973). Sin embargo podemos pensar que sí hubo un entramado de militantes y dirigentes que parecen haber tenido, puertas adentro, algunas tensiones en relación a la decisión de asilarse. ${ }^{22}$ Por ejemplo, en el caso del Partido Socialista, la decisión de asilarse tomada por uno de sus militantes fue compleja, pues recuerda que "las instrucciones era del partido [Socialista], que si había golpe de Estado había que resistir" (Memoria Abierta, Testimonio de Luis Segundo Salazar Esparza, Santiago de Chile, 2013). En el mismo sentido, Beatriz Orrego señala que en su ingreso a la embajada se encontraron "con la grata y desagradable sorpresa de que todos los dirigentes del comité central [del Partido Socialista] estaban asilados desde el día 11" (Memoria Abierta, Testimonio de Beatriz Orrego Villalobos, Santiago, 2013). El "descubrir"23 que los dirigentes del partido ya se encontraban asilados marcó y nutrió de tensiones la convivencia en la embajada:

y en alguna forma se restituyó autoridad política adentro, no teníamos un comité de la Unidad Popular adentro, pero cada uno sabíamos que habían jefes políticos de afuera que estaban adentro en calidad de asilados pero los jefes políticos ahí éramos nosotros, son cosas bien complejas de entender y de explicar también (Memoria Abierta, Testimonio de José Emilio Dollenz Briceño, Santiago de Chile, 2013).

La embajada argentina fue una opción para poner a salvo la vida. Como bien señala Dutrénit (1999: p. 118), los perseguidos políticos de la región fueron convirtiendo al asilo en una estrategia colectiva a medida que iban compartiendo los conocimientos y la información de distintos casos de personas asiladas. La embajada parece haber reunido en poco tiempo un número considerable de personas asiladas. Los relatos subrayan la enorme sorpresa que se generaba al ingresar a la residencia, ya que había una gran cantidad de personas:

21 Sznajder \& Roniger (2013: p. 284) incluyen en este caso al Partido Socialista, el Partido Comunista, el Movimiento de Acción Popular Unitaria, el Partido Radical, la Izquierda Cristiana y el Movimiento de Izquierda Revolucionaria, entre otros asociados a la coalición a favor de Allende.

22 El exilio y el asilo diplomático como nudos de las estructuras políticas chilenas no serán profundizados aquí, pero consideramos que por las marcas narrativas que ocupan en sus relatos, estas experiencias merecen mayores investigaciones.

23 Por ejemplo, otro testimonio que enfatiza esta sorpresa, señala: "ahí cuando entramos lo que había era, pero un regimiento de gente y empezaste a ver que inclusive dentro de la misma embajada los políticos tenían un espacio especial. Ahí estaban los grandes dirigentes que esperábamos que nos dieran conducción política, ¡estaban ahí! (Memoria Abierta, Testimonio de Mario Daniel Pérez Aguilar, Santiago, 2013). 
y cuando entramos nos dimos cuenta que parece que muchos habían hecho el mismo análisis, y nos encontramos con mil quinientas personas adentro, hasta en el baño, y eso fue una epopeya, en donde los milicos impedían el ingreso normal de abastecimiento y en donde había que organizarse para dormir parado, porque no había ni siquiera lugar para recostarse sobre una muralla, éramos setecientas personas adentro, o sea, ahí se puso a prueba la capacidad, la solidaridad y la humanidad del grupo humano que había ahí, ¡que había de todo! (Memoria Abierta, Testimonio de Luis Segundo Salazar Esparza, Santiago, 2013).

Como subraya el entrevistado, en la embajada llegaron a convivir por un breve periodo de tiempo un gran volumen de personas a la vez y de diferentes nacionalidades: chilenos, uruguayos, brasileños, bolivianos, argentinos, entre otros. Algunos medios de prensa señalan que en las primeras tres semanas habrían ingresado aproximadamente cuatrocientas personas llegando a ser en total mil asilados (Clarín, 11/09/2003). Otros números fluctúan entre quinientas y ochocientas personas, aproximadamente (Clarín, 11/11/07; Página 12, 13/09/2013; Memoria Abierta, Testimonios de Juan Tobar, Santiago, 2013; y Albino Gómez, Buenos Aires, 2013). ${ }^{24}$ Si tenemos en cuenta otras experiencias de asilo diplomático, podemos ver que esta magnitud aproximada sería una de las más altas. ${ }^{25}$

\section{La vida cotidiana en la embajada argentina}

$\mathrm{Al}$ igual que en otras experiencias de asilo en la región, para los diplomáticos de la embajada y para sus asilados, la vida cotidiana estuvo sujeta a múltiples cambios. Como explica Dutrénit en el caso de la embajada mexicana en Montevideo, las experiencias del asilo estuvieron marcadas por "el encierro en libertad", lo que supuso reconstruir lo cotidiano en el marco de la excepcionalidad (Dutrénit Bielous, 2011: pp. 133-134). Esta reconstrucción de rutinas, hábitos y costumbres estuvo sujeta además a la cantidad de tiempo en que los asilados permanecieron en la embajada, lo que dependió de cuánto se demorara el Estado territorial en entregar los salvoconductos para poder salir del país. Veamos los aspectos más sobresalientes de la vida en la embajada argentina.

24 Ariel Dorfman (1998) menciona que fueron aproximadamente novecientas personas las que recibieron asilo.

25 Por ejemplo, en 1974 la embajada sueca en Chile reunía un total de setecientos asilados (Camacho, 2006: p. 32). Parte de la imprecisión que surge constantemente sobre el asilo en la embajada argentina tiene que ver con la imposibilidad del acceso público a los fondos documentales de esta legación. 
El ingreso de centenares de personas a la residencia en Vicuńa Mackenna implicó que, inmediatamente, los temas de alimentación, salud e higiene fueran los más urgentes de resolver. El entonces consejero, Albino Gómez, recuerda:

tuve 400 personas [...] la gente se tiraba acá, se tiraba allá, agarraba los almohadones, bueno quedó hecho todo un destrozo, no por querer destrozarlo pero levantaban los almohadones de los sillones para tirarlos en el suelo, de noche tenían que dormir en el suelo, no tenían dónde dormir [...] logré sí sacar mujeres embarazadas o con chicos, chicos, llevarlos a esos tres dormitorios del anexo, bueno ahí no sé si habría 20 o 25 personas en total para tenerlos un poco más protegidos, conseguirles leche, etc. (Memoria Abierta, Testimonio de Albino Gómez, Buenos Aires, 2013).

Parte de la asistencia fue enviada desde Argentina por el gobierno nacional (La Nación, 22/09/1973) y, de acuerdo con Juan Tobar, empleado de la embajada, hubo un aumento en los recursos económicos que permitió que no faltaran remedios, alimentos, colchonetas y frazadas; aunque en algunos relatos se remarcan ciertos manejos confusos en la distribución de los alimentos. ${ }^{26} \mathrm{La}$ vida en la embajada requirió de algunos esfuerzos de organización para evitar el caos cotidiano. Algunas rutinas y tareas fueron pensadas y propuestas por los mismos asilados, que se organizaron por grupos en función de diversos temas; por ejemplo, el grupo de salud, "andaban revisando los baños, los lavamanos, a donde estaba ese comedor chico se hizo una clínica ahí, porque había muchos doctores también acá, estaba bien organizados, no hubo problemas en eso" (Memoria Abierta, Testimonio de Juan Tobar, Santiago, 2013). Otros entrevistados también señalan que mientras un grupo se encargaba de hornear el pan, otro se ocupaba del aseo de los baños. ${ }^{27}$ Un entrevistado subraya que había turnos por grupos:

[el] grupo cero [era] la mujer embarazada, era el primero que comía, y el grupo 1, los niños, y al final los hombres jóvenes, si quedaba un pan, si quedaba una manzana. Y ese grupo era para los derechos de comer, derecho de bańo y derechos de

26 Por ejemplo, se mencionan algunas prácticas que tenían los empleados de la embajada con los asilados en relación a ciertos pagos (en dinero) que debían ofrecer para conseguir alimentos; ante la situación de tener que "pagar para comer" se habría generado una tensión importante entre un grupo de asilados y el encargado de negocios de la embajada. Así, Beatriz Orrego, comenta: "le contamos nosotros [al encargado de negocios], le dijimos que teníamos hambre, así con esas palabras, hambre, porque este caballero vende las cosas y como no tenemos dinero para comprarlo no tenemos que comer, y ahí a este caballero lo mandaron de vuelta a Argentina y ya" (Memoria Abierta, Testimonio de Beatriz Orrego Villalobos, Santiago, 2013).

27 Estas experiencias de organización en la vida cotidiana de una embajada con asilados también se encuentra en otros casos, como el de la embajada mexicana en Chile (Rodríguez, 1999). 
dormir. Porque no cabíamos todos acostados en el piso, no había espacio (Memoria Abierta, Testimonio de Luis Salazar, Santiago, 2013).

En un espacio que no estaba preparado para recibir a tanta gente, la organización fue parte de la respuesta para solucionar distintos problemas, sin embargo, en muchas circunstancias esto no lograba cubrir todas las necesidades. Algunos asilados recuerdan las peripecias de un día "común" en la embajada como un sinfín de esperas: "en la mañana te levantabas, tenías que hacer una fila para poder entrar al baño que te la encargo, tenías que hacer una fila enorme. ¿¿Ducharse? Esa palabra estaba vedada, yo creo que yo me habré duchado a los 15 días que estuve ahí porque ya empezaron a sacar gente y ahí recuerdo que me pude duchar" (Memoria Abierta, Testimonio de Mario Daniel Pérez Aguilar, Santiago, 2013). Por otro lado, una exfuncionaria del ACNUR menciona que en sus visitas a la embajada veía cómo los asilados pasaban frío cuando les cortaban la electricidad, teniendo que cubrirse como podían (Belela Herrera, en MRECIC, 2007: p. 122).

Los aspectos recreativos también eran importantes, pues permitían que los adultos y sobre todo los nińos mantuvieran una actividad creativa que los alejara por momentos de la "excepcionalidad" que estaban viviendo. Por ejemplo, una entrevistada recuerda: "tratábamos de tener actividades... hicimos hoyitos y jugábamos con una pelotita, [...] hacíamos distintas cosas, lectura, otros escuchaban música, y nos pusimos a hacer artesanías, porque había unas palmas que daban una semilla así negra y buscamos clavos, después las barnizábamos y las vendíamos" (Memoria Abierta, Testimonio de Beatriz Orrego Villalobos, Santiago, 2013). Para otro asilado, la misma edificación de la embajada ayudaba a que los momentos de recreación con los nińos fueran posibles: "con los cabros chicos nos entreteníamos, jugábamos, salíamos, corríamos por el jardín [...] éramos privilegiados en relación a otras embajadas, porque la embajada era muy linda y además teníamos un excelente jardín al cual no podíamos acceder por razones obvias pero el patio de atrás era muy bonito" (Memoria Abierta, Testimonio de Mario Ulises Gómez Ramírez, Santiago, 2013). ${ }^{28}$

A las necesidades cotidianas se sumaba la angustia de los asilados por la crítica situación en la que se encontraban: "toda la gente muy nerviosa, muy desesperada, todos con una sensación de pérdida tremenda, de pérdida de lugar, pérdida de país, pérdida de todo tipo, nos sentimos un poco perdidos todos" (Memoria Abierta, Testimonio de Ana María Bussi Vidal, Santiago, 2013). Junto a ello, la fragilidad de las rutinas que se intentaron construir en la embajada argentina

28 Los aspectos lúdicos de la vida de los asilados han sido analizados para el caso de la embajada mexicana en Montevideo, véase Dutrénit (2011). 
estuvo sujeta también a ciertos episodios amargos y confusos marcados por la represión que sufrían muchas personas que llegaban en terribles condiciones físicas y psíquicas, "llegaban muchos mentalmente y físicamente enfermos, unos ya trastornados, ya en la noche no dormía, gritaba nomás y otros que venían del Estadio Nacional golpeados, torturados, puros jóvenes" (Memoria Abierta, Testimonio de Juan Tobar, Santiago, 2013). Así, una parte del espacio físico de la embajada estuvo destinado a la atención de personas que llegaban desde el Estadio Nacional ${ }^{29}$ torturados, "entonces afortunadamente por alguna razón había en ese minuto cinco médicos de los cuales dos eran psiquiatras entonces ellos se hicieron cargo de la gente que venía en peores condiciones" (Memoria Abierta, Testimonio de José Dollenz Briceño, Santiago, 2013).

Además hubo algunos episodios de represión y muerte dentro de la embajada que pusieron a la seguridad interna como tópico central de atención por parte de los funcionarios y de los mismos asilados. El caso más recordado es el crimen de Sergio Gustavo Leiva Molina, uno de los asilados en la embajada que el día 3 de enero de 1974 recibió un disparo efectuado por carabineros desde la calle. ${ }^{30}$ En cuanto sucedió el disparo, en la embajada se trastocó la vida nuevamente, mientras un grupo de asilados asistía a Leiva y lo llevaban a una habitación para atenderlo, los diplomáticos estudiaban la manera de llevarlo bajo protección diplomática al hospital más cercano. ${ }^{31}$ En ese escenario, el reconocido periodista Mario Gómez López, asilado también allí, dio aviso a los medios de prensa, rompiendo con el aislamiento que correspondía al asilo:

Leiva era un buen chiquillo, y ahí tuvimos que tomar... yo entré a las oficinas, no había nadie, no me acuerdo por qué ese día no trabajaban y entonces yo usé el teléfono y avisé en los diarios y lo demás de lo que había ocurrido, de que habían asesinado a este muchacho entonces todos amigos míos, jse llenó de fotógrafos! (Memoria Abierta, Testimonio de Mario Gómez López, Santiago, 2013).

29 El Estadio Nacional fue uno de los primeros centros de detención de Chile y uno de los más importantes, con una gran cantidad de detenidos políticos chilenos y extranjeros, sometidos a torturas físicas severas y prolongadas. Sobre este tema véase Montealegre (2003).

30 Así relata, por ejemplo, uno de los asilados que presenció el hecho: "a él lo matan, lo matan adentro de la embajada, no dentro de la embajada propiamente tal sino que es una historia de un compańero comunista, de la dirección comunista de Valparaíso y al trepar él se le cayeron los documentos y Sergio solo, se fue al fondo a donde se entraba a ver si acaso encontraba los documentos, y se sentó en el muro porque había un nogal, del nogal pasó para el muro, y en el muro para mirar hacia afuera, y había un carabinero en el matorral y pensó seguramente que Sergio se iba a salir y le disparó, eso es lo que sabemos" (Memoria Abierta, Testimonio de Mario Daniel Pérez Aguilar, Santiago, 2013).

31 Nos apoyamos en los testimonios de Beatriz Orrego, José Emilio Dollenz Briceño y Mario Daniel Pérez Aguilar, ya referidos. 
Las memorias y relatos sobre ese hecho expresan la clara sensación de estar en peligro. Esta sensación no se apoyaba solamente en este hecho, sino que en ese breve pero intenso tiempo la violencia era una realidad palpable en cualquier lugar del país:

el concepto que nosotros manejábamos era que la embajada era un territorio seguro que prestaba protección completa y no se podía poner en peligro que en algún minuto entrara la fuerza militar y tomara la embajada. Si ya había bombardeado el Palacio de la Moneda con el Presidente y sus compañeros adentro, ¿por qué no podría haber ocurrido algo similar? (Memoria Abierta, Testimonio de José Emilio Dollenz Briceño, Santiago, 2013).

Una de las respuestas inmediatas consistió en reforzar la vigilancia que desarrollaba el grupo de seguridad interna, formada por los mismos asilados. Uno de ellos relata: "fui parte del grupo de seguridad que funcionaba fundamentalmente en la noche, [para] evitar que la gente se volviera loca o se trastornara e intentara salir, más de algún caso hubo, o que entraran desde afuera gente que no correspondía. Si bien no teníamos más que nuestras propias manos, palos, pero bueno" (Memoria Abierta, Testimonio de Mario Ulises Gómez Ramírez, Santiago, 2013).

Mientras que en la embajada el efecto inmediato que tuvo el crimen de Leiva fue el derrame de más miedos y temores entre los asilados, en Argentina este episodio parece no haber generado serias repercusiones ni tensiones entre ambos gobiernos. Como señala Lucía Abbattista (2013), este hecho solo recibió una protesta por parte del gobierno de Juan Domingo Perón, pero no significó la ruptura de las relaciones con el gobierno chileno; aunque, por otra parte, sí tuvo importantes repercusiones en la comunidad de chilenos organizados en Argentina. Por ejemplo, la Coordinación de Movimientos de Ayuda a Chile (COMACHI) explicaba que este hecho y otras muertes ejecutadas afuera de la embajada eran una clara seńal de que el gobierno chileno estaba profundizando la vigilancia para evitar nuevos ingresos a la embajada (сомасні, Boletin, "Estremecedor relato de un asilado chileno", febrero, 1974).

Vinculado a estos hechos, algunos relatos subrayan la poca presencia que tuvieron los diplomáticos de la embajada ante sus asilados. Para uno de ellos, el asesinato de Leiva hizo que los funcionarios de la embajada se acercaran por primera vez a dialogar (Memoria Abierta, Testimonio de Mario Daniel Pérez Aguilar, Santiago, 2013), mientras que, en otros testimonios, se remarca que los contactos solo se concretaron a la hora de solicitar el asilo, pero que luego de ello lo cotidiano transcurría sin otra comunicación. Una de las asiladas, recuerda: 
Que la embajada nunca abriera sus puertas completamente, la única vez que vi un funcionario fue con la entrevista, nos ponía en una fila, nombre, apellido, edad, ¿pide asilo político? Todo muy frío, despersonalizado, formábamos fila y ya. No teníamos ninguna información. Solamente se acercaba el funcionario y decía quien tiene la autorización para salir (Memoria Abierta, Testimonio de Ana María Bussi Vidal, Santiago, 2013).

Es interesante este rasgo porque contrasta fuertemente con otras experiencias de asilo en las cuales los funcionarios de otras embajadas tuvieron una presencia más marcada en las memorias de sus asilados. Por ejemplo, el renombrado diplomático Harald Edelstam, embajador sueco en Santiago, es uno de los casos más presentes cuando se habla del asilo en Chile ya que expresó una clara voluntad política para poner a salvo la vida de centenares de perseguidos en los años del terror estatal en la región. ${ }^{32}$ En el caso de la embajada argentina, las historias de solidaridad diplomática no parecen haber calado hondo en las memorias de los asilados. ${ }^{33}$ En parte, esta ausencia se puede explicar por los múltiples traslados de distintos consejeros y diplomáticos argentinos desde Santiago a distintos puntos de Latinoamérica que fueron dispuestos por el Ministerio de Relaciones Exteriores de Argentina desde finales de 1973 y durante 1974. Este aspecto también fue subrayado por un grupo de legisladores argentinos, encabezado por Héctor Sandler, ante el pase de diplomáticos que estaban ayudando a los asilados chilenos en la embajada, en particular de Félix Córdoba Moyano, Albino Gómez y del cónsul general Sainz Ballesteros que regresaron a Buenos Aires al poco tiempo de que la residencia estuviera colmada de asilados. Como plantean Cisneros y Escudé (2000), ese grupo de legisladores se preguntaba si no era precisamente la actitud de estos tres diplomáticos de otorgar asilo a los chilenos perseguidos por el régimen de Pinochet lo que habría motivado su regreso a la capital argentina. De hecho, Albino Gómez enfatiza:

No pensé que me fueran a sacar, sobre todo porque no percibíamos por parte de la Junta ninguna presión militar sobre nosotros. No pensé. Me tomó de sorpresa.

32 Parte de esta voluntad política se manifestó en el rescate que realizó de los 54 uruguayos detenidos en el Estadio Nacional y a quienes salvó de ser fusilados (sobre este caso, véase Camacho, 2006). Otro caso renombrado es el de Vicente Muńiz Arroyo, embajador mexicano en Montevideo durante los años 1974 y 1977, cuya actuación también expresó una amplia participación en la protección de personas bajo la figura del asilo. Sobre este tema véase Dutrénit (2011: pp. 161-182). Sobre estos aspectos, recomendamos el documental "De dolor y esperanza. El asilo, un pasado presente", coordinado por Silvia Dutrénit Bielous, Carlos Hernández Marines y Guadalupe Rodríguez de Ita (Instituto Mora, México, 2002).

33 En algunos casos, los entrevistados señalan no haber visto durante la estadía en la embajada a ningún diplomático (Memoria Abierta, Testimonio de Luis Salazar, Santiago, 2013). 
Recibí un cable, donde decía que debía abandonar el país en 24hs. Y así salimos. [...] El decreto de prescindibilidad salió el primero de enero de 1974 y empecé mi lucha para saber. No obtuve ninguna respuesta. Para el canciller Vignes yo era marxista, leninista, todo. Tuve buena prensa pero yo quería que el ministerio explicara por qué me había sacado (Memoria Abierta, Testimonio de Albino Gómez, Buenos Aires, 2013).

Podemos pensar que esta discontinuidad en las funciones de los diplomáticos durante la coyuntura del golpe militar en Chile hasta principios de 1974 podría ser una de las razones por las cuales los asilados no llegaron a establecer un vínculo con los funcionarios a cargo. Por supuesto que esto no quiere decir que el personal de la embajada no haya intervenido para la protección de las personas que allí estaban, pero sí nos permitiría distinguir distintos niveles de solidaridad con los perseguidos. Por otro lado, es importante subrayar que la ausencia de estos diplomáticos habría significado el cierre de las comunicaciones entre la embajada y organismos internacionales en Santiago, como el ACNUR, que estaban trabajando juntos para obtener los permisos de salida de los asilados. Al respecto, Belela Herrera señala que Gómez y Córdova Moyano fueron las figuras más importantes en el entramado de solidaridad hacia los asilados pero cuando se debieron retirar "se cortó" la posibilidad de ingresar a la embajada argentina y por lo tanto, de seguir ayudando (Belela Herrera, en MRECIC, 2007: p. 121). La reconocida escritora Tununa Mercado relata que en Buenos Aires, el nombre de Albino Gómez se transmitía en la boca de los refugiados de distintas nacionalidades "que decían que él les había abierto las puertas de la Embajada Argentina en Chile, que los había salvado, que había sido providencial que él estuviera para recibirlos, organizarlos y darles techo y pan, que es como suelen describirse a escala humana las acciones de refugio diplomático" (El Arca Digital, s/f).

\section{Los asilados arriban a la Argentina}

Si los ingresos y la vida cotidiana en la embajada se desarrollaron con dificultades, incertidumbres y miedos, las salidas hacia Argentina tampoco estuvieron exentas de contrariedades. Uno de los problemas más importantes tuvo que ver con la entrega de los salvoconductos, es decir, de los documentos oficiales que debe gestionar el Estado asilante (en este caso, Argentina) ante el Estado territorial (Chile) para que autorice las salidas del país.

En esta instancia de la experiencia del asilo hubo distintas complicaciones. Una de ellas fue que el régimen militar chileno no siempre aprobaba los 
documentos para que las personas se fueran del país. Así, un asilado destaca las largas listas con nombres que se distribuían en la embajada con la aclaración de "diferido" al lado de algunos de ellos, lo que significaba que no se contaba con esa aprobación (Memoria Abierta, Testimonio de Mario Daniel Pérez Aguilar, Santiago, 2013). La mayoría de estas largas esperas para salir se debían a que las personas estaban siendo investigadas por el régimen militar chileno. También hubo casos en los que fue el gobierno argentino el que demoró esas gestiones. Aquí debemos recordar, por ejemplo, que inmediatamente después del golpe, hubo 278 chilenos que tenían la aprobación para irse pero que no podían hacerlo porque el gobierno argentino no lo autorizaba (Cisneros \& Escudé, 2000). Incluso, el hecho de que los viajes hacia Argentina se realizaran en tandas de cien personas, responde a que las tareas de inteligencia realizadas por la policía argentina no podía superar ese número de investigaciones por semana (La Nación, 1/10/1973). Como explica Abbattista (2014), estas investigaciones pasaron a engrosar los expedientes que los servicios de inteligencia de la Policía difundieron a las distintas fuerzas de seguridad en ese país y que sirvieron a la represión estatal en años posteriores. ${ }^{34}$

En consecuencia, la espera por el salvoconducto significó para algunos de estos asilados, "una lucha más" dentro de lo que fue la vida en la embajada (Memoria Abierta, Testimonio de José Emilio Dollenz Briceńo, Santiago, 2013). Cuando los diplomáticos recorrían la embajada con las listas de aprobados, los asilados se encontraban atrapados entre sensaciones complejas, entre la pena, la incertidumbre ${ }^{35}$ y la alegría, "algunos te felicitaban y uno no entendía las felicitaciones" (Memoria Abierta, Testimonio de Mario Ulises Gómez Ramírez, Santiago, 2013). Una vez obtenido el permiso, los asilados subían a un bus dispuesto por la embajada en el que se trasladaban hasta el aeropuerto ${ }^{36}$ y allí los esperaba un avión de la Fuerza Aérea Argentina para cruzar la frontera. Uno de ellos subraya esta sensación "rara" de la salida:

34 Magdalena Lantieri, actual directora del Archivo de la DippBa, cuenta al respecto: "En los documentos de inteligencia policial se relata la preocupación del Estado argentino respecto del arribo de esos asilados en nuestro país que habilitó que cada una de esas personas fuera 'fichada' por la Policía Federal en su ingreso (con el detalle de sus antecedentes ideológicos y la evaluación del nivel de peligrosidad que representaba)." (Página 12, 13/09/2013).

$35 \mathrm{Al}$ rememorar su salida de la embajada, uno de ellos cuenta: "sentí mucha pena dejar el país, porque te ibas a enfrentar a un país que no lo conoces, no sabías qué iba a ocurrir ahí, pena, temor, incertidumbre" (Memoria Abierta, Testimonio de Mario Daniel Pérez Aguilar, Santiago, 2013).

36 Por ejemplo, uno de los asilados recuerda: "nos espera un bus en la mańana, subimos todos quienes íbamos, íbamos bastante nerviosos, preocupados porque era perder la seguridad que nos había brindado la embajada, entonces la inmunidad diplomática puesta en un bus, pero eso ya implicaba una cierta preocupación, desde caminar a subir al bus y en el trayecto del bus al aeropuerto" (Memoria Abierta, Testimonio de Mario Ulises Gómez Ramírez, Santiago, 2013). 
porque estás saliendo de un mundito que te habías creado a una incertidumbre, por un pasadizo de carabineros que hacen como un callejón, subimos al bus, el bus parte hacia el aeropuerto y nosotros miramos por la ventana y veíamos que la gente caminaba normal y nosotros íbamos ahí adentro hacia una incertidumbre total derrotados, y el bus avanzaba y yo veía a la gente normal, caminando por la calle por la alameda (Memoria Abierta, Testimonio de Luis Salazar, Santiago, 2013).

Es sugerente la imagen que se entreteje en este recuerdo, de un país que parecía "normal" mientras se producían los destierros de centenares de ciudadanos que, como estos asilados, transitaban sus salidas de forma silenciosa. Por otro lado, muchos de ellos destacan también, que la salida hacia Argentina fue pensada como un impasse, como un momento que sería breve y que les permitiría, en algunos casos, reorganizarse para volver al país. ${ }^{37}$

Además de las complejidades que presentamos, en la instancia de la salida existieron algunas medidas tomadas por el gobierno argentino que condicionaron el ingreso de los chilenos a su territorio. Un hecho importante fue el caso de los 112 chilenos que habían arribado al hotel Ezeiza y que fueron inmediatamente detenidos por la policía. Esta detención fue denunciada mediante la presentación de un recurso de amparo a través del cual, el juez Miguel Inchausti, ordenó la liberación; sin embargo, el gobierno nacional no acató esta sanción y en su lugar, exigió que los asilados abandonaran el país en veinticuatro horas (Bufano, 2005). Ana María Bussi recuerda: "y llegamos a ese hotel, al Hotel Ezeiza. Un hotel muy de lujo, pero los primeros pisos, los últimos pisos es una cárcel internacional, que muy poca gente sabía, yo creo. Eran cuartos pero que pusieron un gendarme en cada puerta, cuando nosotros levantamos el teléfono, decía: usted está detenida e incomunicada, sírvase colgar este teléfono" (Memoria Abierta, Testimonio de Ana María Bussi Vidal, Santiago, 2013).

Es importante destacar que los primeros contingentes de asilados llegaron a Buenos Aires en octubre de 1973, un mes después del golpe militar y que, para ese entonces, la situación política en Argentina estaba atravesada por importantes conflictos internos entre la radicalización política de la juventud peronista y de izquierda y el gobierno de Perón que gobernaba a partir de las premisas de "pacificación social", "condena a la subversión” y "depuración ideológica" (Franco, 2012: pp. 50-54). La llegada de los asilados se inscribió en ese marco. En ese sentido, pueden explicarse también algunos informes elaborados por la DIPPBA

37 Por ejemplo, un asilado señala: "mi preocupación era organizar la vida adentro y salir rápido de la embajada hasta Argentina y luego organizar el regreso, no te podría inventar otra razón de vida que no era salir rápido de Chile y volver rápido a seguir luchando" (Memoria Abierta, Testimonio de José Emilio Dollenz Briceño, Santiago, 2013). 
a finales de 1973, en los que se construye una mirada criminalizante sobre los chilenos en Argentina. Por ejemplo, en uno de esos informes se enfatiza: "Los mismos [exiliados chilenos], al igual que los extranjeros residentes que también se acogieron al derecho de asilo, son en su mayoría guerrilleros y/o elementos relacionados con organizaciones subversivas, difiriendo fundamentalmente con los típicos 'asilados políticos' que tradicionalmente ha recibido nuestro país a lo largo de su historia" (Dippba, Parte de Información, 27/73, 6/11/1973, Mesa Referencia, Leg. 16998, Tomo I).

Otras experiencias que dan cuenta de este control fueron las disposiciones que establecían que los arribos aéreos de los asilados ocurrieran lejos de la ciudad de Buenos Aires, en otras regiones internas del país (La Opinión, 6/10/1973). Como señala Bufano (2005), esto ya formaba parte de los discursos públicos del presidente Perón en los que indicaba que, si bien se otorgaría el asilo por cuestiones de derecho internacional, los extranjeros serían "confinados" a lugares distantes, como Misiones o "la selva". Por ejemplo, Mario Ulises Gómez Ramírez viajó en octubre de 1973 y recuerda que en el mismo vuelo hacia Ezeiza se enteraron de que el trayecto había cambiado: "ya deberíamos haber aterrizado y cuando empezamos a ver para abajo, empezamos a ver agua, y habían matorrales, planta, agua, esto parece más un indicador de antesala de la selva y ahí nos empezamos a preocupar y a exigir que nos dijeran" (Memoria Abierta, Testimonio de Mario Gómez Ramírez, Santiago, 2013). En lugar de aterrizar en Buenos Aires, el avión los llevó hasta la ciudad de Corrientes, en donde fueron recibidos por personal de la gendarmería y llevados a un hotel manteniendo fuertes controles sobre ellos.

En el mismo tono se desarrolló el arribo de Mario Daniel Pérez Aguilar en enero de 1974. En su caso, también fue llevado a una ciudad alejada de Buenos Aires: Bahía Blanca. Su experiencia estuvo atravesada por dos caras diferentes: por un lado, "por la solidaridad de los argentinos con los chilenos" y, por el otro, por la profundización de la violencia paraestatal de esos años. En este último punto, el entrevistado, señala:

ya después empiezan a marcar las casas en donde vivíamos, la Triple A [Alianza Anticomunista Argentina], 'fuera los comunistas' y qué se yo, y ya se veía como que venía el golpe en Argentina también. Entonces nosotros arrancando de un golpe, estábamos cayendo al inicio de otro y no podíamos salir nosotros de Bahía Blanca porque teníamos, para decirlo de alguna forma, teníamos la ciudad por cárcel (Memoria Abierta, Testimonio de Mario Daniel Pérez Aguilar, Santiago, 2013).

En el mismo sentido, otro asilado señala que su experiencia de "alegría por salir del país” fue también una experiencia "dramática” por la fuerte represión 
que "los grupos de ultraderecha" en Argentina dirigieron hacia los asilados (Memoria Abierta, Testimonio de José Emilio Dollenz Briceño, Santiago, 2013).$^{38}$ La persecución ideológica y política, sería parte también de la experiencia de los funcionarios de organizaciones humanitarias en Argentina. Como explica Oldrich Haselman -representante regional del ACNUR para América Latina en esos años-, fue sobre todo a partir de la muerte de Perón, en julio de 1974, que las áreas de protección de refugiados fueron amenazadas y violentadas y muchos de ellos deportados hacia otros países (Haselman, en MRECIC, 2007: p. 115).

Sin lugar a dudas, las experiencias de estos y otros asilados en Argentina desde 1973, tuvieron distintos derroteros de cara a lo que fue posteriormente el golpe militar de marzo de 1976. Otras experiencias de chilenos no asilados remarcan también esta sensación de incertidumbre en el país. Por ejemplo, Adriana Moreno partió hacia Argentina en 1974 por sus propios medios, pues consideraba que tanto la categoría de refugiado como de asilado podían ser herramientas perjudiciales para su vida en ese país. Las experiencias cercanas le permitieron concluir a esta entrevistada que lo mejor era no pedir asilo, para de esa manera poder pasar inadvertida:

Yo tenía unos grandes amigos que eran asilados brasileros en Chile que salieron asilados por la embajada argentina y allá me ubiqué nuevamente con ellos... estaban viviendo en el ámbito de asilados que llegaban de Chile... yo no iba ni en calidad de asilada ni de refugiada, de hecho yo no me refugié... porque lo que yo quería era sobrevivir [...] lo que vi en Argentina era que la situación política era muy complicada y que además empezaban a perseguir a la gente chilena. Vivían en un nivel de inseguridad muy brutal, de hecho mi amigo Eduardo Carvallo ${ }^{39}$ desaparece en la Argentina, siendo que había sido asilado, o sea protegido por el gobierno de Argentina (Entrevista a Adriana Moreno Fuenzalida, Santiago, 2013).

Las difíciles experiencias de asilo en Argentina estuvieron fuertemente atravesadas por las dinámicas políticas internas del peronismo en el poder. Como explica Cecilia Azconegui (2014), las primeras respuestas del peronismo ante el golpe de Pinochet y mucho más antes con los asilados, fueron poco claras. Por un lado, el breve gobierno de Lastiri tuvo una posición ambigua entre la

38 Así relata: "tenía sensación de alegría por irse a Argentina y pasar, me imaginaba, a una vida un poco más normal. Pero ahí empezó el otro drama porque yo no lo alcancé a ver, los tres primeros viajes los llevaron derecho a Ezeiza y los grupos de ultraderecha en Argentina comenzaron a atacar los lugares a donde estaban los asilados chilenos en Buenos Aires" (Memoria Abierta, Testimonio de José Emilio Dollenz Briceño, Santiago, 2013).

39 De nacionalidad brasileña, vivió en Chile y se refugió en Argentina tras el golpe de Estado de 1973. 
condena y la aceptación del gobierno militar chileno en la que finalmente se reconoció la soberanía del régimen de Pinochet. Pero, por otro, hubo una recepción preferencial ${ }^{40}$ del gobierno de Perón a los chilenos en relación a otros asilados latinoamericanos, a los que solo se recibió de modo transitorio. Junto a ello, profundizando la complejidad del proceso, hubo una fuerte cristalización del tema de los refugiados y/o exiliados como parte de un "problema de seguridad nacional". Este aspecto se fue consolidando desde mediados de $1974 \mathrm{y}$ con mayor claridad en 1975, lo que obligó a muchos asilados y extranjeros en el país a iniciar un segundo exilio hacia otros continentes.

Las ambiguas posiciones del peronismo en esa coyuntura se encuentran aún pendientes de una investigación exhaustiva. Para comprender las experiencias del asilo en su complejidad será importante tenerlas en cuenta, pues los relatos aquí recuperados ofrecen distintos matices sobre el caso. Por ejemplo, una exiliada subraya: "en el peronismo hubo gente muy solidaria como hubo gente que nos perseguía también... pero en su mayoría, era muy solidario con los chilenos, yo por lo menos, lo que viví eran gestos de mucha solidaridad" (Entrevista a Adriana Moreno Fuenzalida, Santiago, 2013). De hecho, los agradecimientos hacia Argentina por parte de los asilados chilenos son frecuentes, a pesar de las experiencias de detención y persecución que se vivieron en algunos casos. ${ }^{41}$ Estos indicios, así como los relatos recorridos sobre la recepción y cotidianidad en la embajada, nos permiten cuestionar las imágenes monolíticas que circulan sobre este tema. ${ }^{42}$ Podemos repensar entonces esta coyuntura de incertidumbre política y de crisis general en la región, reconociendo múltiples

40 Azconegui (2014) destaca dos medidas que permiten pensar en un gesto político hacia la problemática de los exiliados: la aprobación de la amnistía en 1974 que permitía a los extranjeros regularizar su situación ante la Dirección Nacional de Migraciones y la creación de la Comisión Coordinadora de Acción Social (CCAS) en la que intervino el gobierno junto al ACNUR y a distintas organizaciones cristianas, para recibirlos y atenderlos en el país, aunque ambas medidas no hayan sido suficientes para la protección de los chilenos en Argentina.

41 Por ejemplo, Luis Salazar enfatiza: "y yo diría que si hay algo que agradecerle al pueblo argentino es que haya tenido la solidaridad, primero la valentía de recibirnos y haberse hecho cargo, con todo lo que significa en ese minuto hacerse cargo de setecientas personas que estaban ahí adentro y responder por ellos y eso es un agradecimiento permanente" (Memoria Abierta, Testimonio de Luis Salazar, Santiago, 2013).

42 En 2007, el presidente Néstor Kirchner, entregó una placa a la embajada argentina en Santiago que hoy se encuentra en el acceso a la residencia. Esta placa subraya el carácter solidario del gobierno, en una estructura narrativa que podría ocluir otras memorias. Así, reza: "En este predio se asilaron durante varios meses centenares de ciudadanos chilenos y de otros países que fueron víctimas de persecución política a partir del golpe de Estado contra el gobierno democrático de Salvador Allende. Conmemoramos aquellas jornadas reivindicando el compromiso de los pueblos chileno y argentino por la defensa de los valores de la solidaridad, la democracia, la libertad y el respeto por los derechos humanos". 
actores, políticas e intereses, algunas de las cuales imprimieron acciones solidarias en un marco que avanzaba gradualmente hacia políticas más represivas y de exclusión. ${ }^{43}$

\section{Consideraciones finales}

A lo largo de este artículo recorrimos distintas trayectorias y experiencias de asilo de chilenos y chilenas que encontraron en la embajada argentina en Santiago un lugar de protección. Esta investigación nos permitió avanzar en el conocimiento de algunas características importantes de estas experiencias y de otras tensiones que también las atravesaron.

A partir de los relatos aquí recuperados podemos afirmar que la búsqueda del asilo diplomático fue resultado de una decisión tomada en medio de la incertidumbre, sin mucha planeación; decisión en la cual la embajada argentina "emergió" como opción "a la mano", por su ubicación en el mapa urbano de Santiago y por la inmediatez de su frontera con Chile, lo que significaba en el imaginario de los asilados permanecer "cerca" del país. Junto a ello, vimos que las condiciones de vida dentro de la embajada fueron difíciles de solucionar en lo inmediato y que requirieron de la organización y de la buena convivencia de los asilados y diplomáticos. Pero aún más, la experiencia de este asilo estuvo marcada por diferentes escalas de solidaridad que nos permitirían postular que los diplomáticos de la embajada actuaron por su cuenta y a veces a contrapelo de las posiciones políticas más generales que se tomaban en Argentina con respecto al caso chileno.

Sobre los distintos aspectos de esta experiencia aún queda mucho por recorrer. Consideramos que uno de los principales desafíos consiste en indagar con mayor profundidad sobre las prácticas políticas de los actores diplomáticos, gubernamentales y estatales que operaron de distintas maneras en el otorgamiento del asilo y en los recibimientos de exiliados chilenos - y de extranjeros- en Argentina. En estrecha relación, resulta fundamental que las investigaciones amplíen la mirada temporal y geográfica de las experiencias del asilo chileno en Argentina y que, además, se realicen comparaciones rigurosas con otros casos.

43 Esto también es recuperado por Azconegui (2014), cuya investigación demuestra que la sobrevivencia de los refugiados chilenos bajo la dictadura militar argentina estuvo sometida a las complejas tramas sociales de vínculos y contactos con distintas personas en el país que a veces posibilitaron que algunas disposiciones estatales para la persecución y expulsión de los migrantes no fuesen totalmente acatadas por las personas encargadas de hacerlo. 
En definitiva, los relatos aquí recuperados nos permitieron adentrarnos a la memoria de una experiencia poco explorada hasta ahora y que se encuentra alimentada por recuerdos dolorosos y silenciados pero también por gestos y acciones de solidaridad y protección que merecen seguir siendo interpelados.

\section{Referencias}

\section{Bibliografía}

Abbattista, L. (2014). La política estatal del peronismo ante el exilio chileno: el caso de la atención a los asilados en la Embajada argentina en Santiago tras el Golpe de 1973. Ponencia presentada en las II Jornadas de Trabajo sobre Exilios Políticos del Cono Sur en el Siglo xx. Agendas, problemas y perspectivas conceptuales, 5, 6 y 7 de noviembre de 2014, Montevideo.

Abbattista, L. (2013). La campaña contra los “extremistas extranjeros” tras el Golpe de Estado en Chile. El caso de la Embajada argentina en Santiago, inédito.

Aguirre, E. \& Chamorro, S. (2008). Memoria gráfica del exilio chileno. 1973-1989. Santiago de Chile: OchoLibros.

Alto Comisionado de las Naciones Unidas para los Refugiados (ACNUR). (2000). La situación de los refugiados en el mundo: Cincuenta años de acción humanitaria. Recuperado de http:// www.acnur.org/publicaciones-SRM/

Azconegui, C. (2014). Chilenos en Argentina, entre la protección del Alto Comisionado de las Naciones Unidas para los Refugiados (ACNUR) y la política de expulsión de la dictadura militar. En Jensen, S. \& Lastra, S. (Eds.). Exilio, represión y militancia. Nuevas fuentes y nuevas formas de abordaje de los destierros de la Argentina de los años setenta (pp. 215-250). La Plata: Editorial de la Universidad Nacional de La Plata.

Bufano, S. (2005). Perón y la Triple A. Revista Lucha Armada en la Argentina, (3), 20-35.

Camacho, F. (2006). Los asilados de las Embajadas de Europa Occidental en Chile tras el golpe militar y sus consecuencias diplomáticas: El caso de Suecia. European Review of Latin American and Caribbean Studies, (81), 21-41. Recuperado de http://www.erlacs.org/index.php/ erlacs/issue/view/540

Cisneros, A. \& Escudé, C. (2000). Historia general de las relaciones exteriores de la República Argentina. Las relaciones exteriores de la Argentina subordinada, 1943-1989, tomo XIV. 
Buenos Aires: Grupo Editor Latinoamericano. Recuperado de http://www.argentina-rree .com/14/14-014.htm

Comisión Interamericana de Derechos Humanos (CIDH). (1974). Informe sobre la situación de los derechos humanos en Chile. Recuperado de http://www.cidh.org/countryrep/Chile74sp/ Indice.htm

Del Pozo, J. (2006). Exiliados, emigrados y retornados chilenos en Europa y América 1973-2004. Santiago de Chile: RIL.

Dorfman, A. (1998). Rumbo al sur, deseando el norte. Un romance en dos lenguas. Barcelona: Planeta.

Dutrénit Bielous, S. (2011). La embajada indoblegable. Asilo mexicano en Montevideo durante la dictadura. Montevideo: Fin de Siglo Editorial/Instituto de Ciencia Política.

Dutrénit Bielous, S. (1999). Sobre la percepción y decisión políticas de aplicar el asilo diplomático: una reflexión de experiencias latinoamericanas. América Latina Hoy. Revista de Ciencias Sociales, (22), 111-118.

Franco, M. (2012). Un enemigo para la nación. Orden interno, violencia y "subversión", 19731976. Buenos Aires: Fondo de Cultura Económica.

Gatica, M. (2010). ¿Exilio, migración, destierro? Los trabajadores chilenos que se asentaron en el Noreste de Chubut a partir de Septiembre de 1973: Memorias, historias e implicancias. Tesis de doctorado en Historia, Universidad Nacional de La Plata. Recuperado el 10 de julio de 2012 de http://www.memoria.fahce.unlp.edu.ar/tesis/te.377/te.377.pdf

Jensen, S. (2011, mayo). Exilio e Historia reciente. Avances y perspectivas de un campo en construcción. Aletheia. Revista de la Maestría de Historia y Memoria, 1(2). Recuperado de http:// www.aletheia.fahce.unlp.edu.ar/splash

Ministerio de Relaciones Exteriores, Comercio Internacional y Culto (MRECIC). (2007). Testimonios de la solidaridad internacional. Buenos Aires: MRECIC.

Montealegre, J. (2003). Frazadas del Estadio Nacional. Santiago: LOM.

Oñate, R., Wright, T., Espinoza, C., Soto, A. \& Galleguillos, X. (2006). Exilio y retorno. Santiago de Chile: Lom.

Paredes, A. (2007). Las condiciones de vida de los exiliados chilenos en Mendoza, 1973-1989. Tesis de doctorado en Historia, Facultad de Humanidades y Ciencias de la Educación, Universidad Nacional de La Plata. 
Rebolledo, L. (2006). Memorias del desarraigo: testimonio de exilio y retorno de hombres y mujeres de Chile. Santiago: Editorial Catalonia.

Rodríguez de Ita, G. (1999). Experiencias de asilo registradas en embajadas mexicanas. En Dutrénit Bielous, S. \& Rodríguez de Ita, G. (Coords.). Asilo diplomático mexicano en el Cono Sur. México: Instituto de Investigaciones Dr. José María Luis Mora.

Sznajder, M. \& Roniger, L. (2013). La politica del destierro y el exilio en América Latina. Ciudad de México: Fondo de Cultura Económica.

Yankelevich, P. (2009). Ráfagas de un exilio. Argentinos en México (1974-1983). Ciudad de México: El Colegio de México.

\section{Hemerografía}

Clarín, Buenos Aires, Argentina.

La Nación, Buenos Aires, Argentina.

Página 12, Buenos Aires, Argentina.

El Arca Digital. (s/f). Recuperado y consultado el 23 de junio de 2013 en http://www.elarcadigital .com.ar/modules/revistadigital $/$ articulo.php?id=244

Dippba, Mesa Referencia, Leg. 16998, Tomo I. Archivo de la Comisión Provincial por la Memoria, La Plata, Argentina.

\section{Entrevistas}

Adriana Moreno Fuenzalida, 2013, Santiago. Entrevista realizada por Carla Peñaloza

Albino Alberto Gómez, 2013, Buenos Aires, Archivo Oral Memoria Abierta

Ana María Bussi Vidal, 2013, Santiago de Chile, Archivo Oral Memoria Abierta

Beatriz Orrego Villalobos, 2013, Santiago de Chile, Archivo Oral Memoria Abierta

José Emilio Dollenz Briceño, 2013, Santiago de Chile, Archivo Oral Memoria Abierta

Luis Segundo Salazar Esparza, 2013, Santiago de Chile, Archivo Oral Memoria Abierta 
Mario Daniel Pérez Aguilar, 2013, Santiago de Chile, Archivo Oral Memoria Abierta

Mario Gómez Ramírez, 2013, Santiago de Chile, Archivo Oral Memoria Abierta

Recibido el 21 de enero de 2015. Aceptado el 21 de agosto de 2015. 